\section{Socioeconomic deprivation and inequalities in lung cancer: time to delve deeper?}

\author{
Helen A Powell
}

Inequalities in lung cancer care between the richest and poorest in society attract attention and rightly so; the disease is most prevalent and survival poorest in those who are deprived. ${ }^{1}$ Through improved awareness, earlier diagnosis and higher rates of curative treatment, predominantly by surgical resection, we have seen improvements in lung cancer survival over the last decade. Unfortunately, there is evidence to suggest that deprived people are less likely to benefit from any of these interventions compared with the more affluent. Socioeconomic deprivation is associated with reduced participation in lung cancer screening trials. $^{2}$ This is due, at least in part, to perceptions that lung cancer is an uncontrollable, self-inflicted, smokers' disease. ${ }^{3}$ Encouraging results from a study of 'Lung Health Checks' in Manchester suggest that it is possible to reach more deprived people if the service is designed appropriately. ${ }^{4}$

Survival differences between the most and least deprived patients with lung cancer may be related to comorbidity; it is well recognised that overall survival from cancer is worse in poorer people. ${ }^{5}$ In lung cancer specifically, this may reflect differences in treatment rates and, even without the specific effects of socioeconomic variation, there are geographical variations in lung cancer treatment rates, attributed by some to varying practice between multidisciplinary teams (MDT). ${ }^{6}$ In this issue of Thorax, Belot et $a l^{7}$ add to the growing body of evidence that the higher the level of deprivation, the less likely people are to have surgery for lung cancer. The focus of the study is factors affecting surgical resection which is described as 'major' but is assumed to be equivalent to surgery with curative intent. Also considered were age, stage, COPD, cerebrovascular disease and heart failure. Unsurprisingly, older people with advanced stage lung cancer and comorbidities were least likely to have had surgery. These

Correspondence to Dr Helen A Powell, Thoracic Medicine, Frimley Park Hospital, Frimley Health NHS Foundation Trust, Frimley GU16 7UJ, UK;

helen.powell5@nhs.net factors did not completely explain the variation by socioeconomic status. The study tells us that the deprived people were less likely to have had surgery, but cannot explain why this was the case. There are two main hypotheses for this: (1) deprived patients were less likely to be assessed as fit enough, that is, there is comorbidity associated with deprivation that is not accounted for in the study, and thus they were not offered surgery, or (2) they were deemed fit enough but declined the recommended treatment.

One factor influencing fitness which Berlot and colleagues were not able to account for is whether or not patients smoked. We know that rates of smoking are significantly higher in more deprived areas, ${ }^{8}$ and are linked to development of lung cancer and in the pathogenesis of many comorbidities which may preclude surgery. Heavy smoking may affect severity of COPD and smoking itself may reduce the likelihood of patients being offered or accepting of surgery, despite clear recommendations that one should not wait for a patient to stop smoking before offering lung cancer resection. Obesity, alcohol and substance abuse are also more prevalent among deprived people and may contribute to an assessment that a patient is not fit for surgery. We also know that risk prediction models based on clinical factors such as performance status do not perform particularly well in trying to predict postoperative mortality, ${ }^{9}$ and there is variation in practice between surgeons in how they assess fitness for surgery. More deprived patients with a higher incidence of smoking (and therefore related comorbidities) have poorer health outcomes and survival overall, ${ }^{10}$ and may be less likely to be deemed 'fit' either through subjective or objective measures (such as cardiopulmonary exercise testing) than less deprived (more affluent) patients with the same performance status, age, stage, and so on.

We do not know how many patients in this study were offered surgery but declined. In a study based in the USA, 3\% of 166000 patients with stage $1 \mathrm{~A}$ lung cancer who were offered surgery, 11\% of those offered chemotherapy and 6\% of those offered radiotherapy declined, and poorer people were more likely to decline recommended treatment. ${ }^{11}$ This would be an interesting study to conduct in the UK where treatment is free to all, and also in other European countries with free healthcare and better lung cancer survival. There is very little research looking at why patients turn down recommended treatment but it is likely to be due to a combination of psychosocial factors and different health behaviours such as willingness to seek medical advice. Anecdotally, patients may have a fear of hospitals, an unwillingness to venture into an unknown larger town or city, be socially isolated with no-one to care for them after treatment, or have caring or financial commitments that would suffer if they spent time in hospital and recovering from surgery. Population-based data suggest that increasing distance from the surgical centre reduces the likelihood of patients having surgery. ${ }^{12}$ If this is due to financial pressures and people being unable or unwilling to travel long distances for treatment it is likely to affect deprived people more than affluent. Interestingly, in another UK study there was no association between socioeconomic status and likelihood of having surgery for lung cancer after accounting for the finding that patients first seen at a surgical centre were more likely to receive surgery than those first seen at a peripheral hospital. ${ }^{13}$ If surgical services are centralised due to evidence suggesting that higher case volume is associated with better outcomes, this needs to be balanced with access in order not to discriminate against people who are unable or unwilling to travel a long distance for treatment. ${ }^{14}$

There is compelling evidence for social inequalities affecting whether or not patients have surgery for lung cancer, which cannot be explained simply by differences in age, performance status and a limited number of comorbidities. With earlier detection through awareness campaigns and the introduction of lung cancer screening in the UK, we hope that curative surgery will be an option for a much higher proportion of patients. The more deprived patients may be harder to engage in such programmes and treatment may also present a challenge. The only way to unpick this is to examine each patient on a level that routinely collected data cannot provide; to delve into patient understanding, preference and choice and see whether this is what precludes 
treatment, or whether they are truly less fit in a way that is not represented by crude assessments such as performance status and a selection of comorbidities. A prospective, more qualitative study of patients who appear on paper to be fit but do not receive surgery, with knowledge of the MDT recommended treatment, is more likely to determine whether there are modifiable non-clinical factors which really influence treatment decisions.

Contributors HAP was the only contributor to this editorial.

Funding The authors have not declared a specific grant for this research from any funding agency in the public, commercial or not-for-profit sectors.

Competing interests None declared.

Patient consent Not required.

Provenance and peer review Commissioned; internally peer reviewed.

C Author(s) (or their employer(s)) 2019. No commercial re-use. See rights and permissions. Published by BMJ.

\section{Check for updates}

To cite Powell HA. Thorax 2019;74:11-12.

Accepted 1 October 2018

Published Online First 31 October 2018

\section{GLinked}

http://dx.doi.org/10.1136/thoraxjnl-2017-211395

Thorax 2019:74:11-12.

doi:10.1136/thoraxjnl-2018-212362

\section{REFERENCES}

1 Riaz SP, Horton M, Kang J, et al. Lung cancer incidence and survival in England: an analysis by socioeconomic deprivation and urbanization. J Thorac Oncol 2011;6:2005-10.

2 Quaife SL, Marlow LAV, McEwen A, et al. Attitudes towards lung cancer screening in socioeconomically deprived and heavy smoking communities: informing screening communication. Health Expect 2017;20:563-73.

3 McRonald FE, Yadegarfar G, Baldwin DR, et al. The UK Lung Screen (UKLS): demographic profile of first 88,897 approaches provides recommendations for population screening. Cancer Prev Res 2014;7:362-71.

4 Crosbie PA, Balata H, Evison M, et al. Implementing lung cancer screening: baseline results from a community-based 'Lung Health Check' pilot in deprived areas of Manchester. Thorax 2019;74:11-12.

5 Cella DF, Orav EJ, Kornblith AB, et al. Socioeconomic status and cancer survival. J Clin Oncol 1991;9:1500-9.

6 Møller H, Coupland VH, Tataru D, et al. Geographical variations in the use of cancer treatments are associated with survival of lung cancer patients. Thorax 2018;73:530-7.

7 Belot A, Fowler H, Njagi EN, et al. Association between age, deprivation and specific comorbid conditions and the receipt of major surgery in patients with non-small cell lung cancer in England: A population-based study. Thorax 2019;74:11-12.

8 Wise J. UK survey confirms link between deprivation and smoking. BMJ 2014;348:g2184.

9 O'Dowd EL, Lüchtenborg M, Baldwin DR, et al. Predicting death from surgery for lung cancer: A comparison of two scoring systems in two European countries. Lung Cancer 2016;95:88-93.

10 Stringhini S, Carmeli C, Jokela M, et al. Socioeconomic status and the $25 \times 25$ risk factors as determinants of premature mortality: a multicohort study and meta-analysis of 1.7 million men and women. Lancet 2017;389:1229-37.

11 Balekian AA AS, Kim AA. Refusal of Recommended Care for Non-Small Cell Lung Cancer. American Journal of Respiratory and Critical Care Medicine 2018;197.

12 Tracey E, McCaughan B, Badgery-Parker T, et al. Survival of Australian lung cancer patients and the impact of distance from and attendance at a thoracic specialist centre: a data linkage study. Thorax 2015;70:152-60.

13 Rich AL, Tata LJ, Free CM, et al. Inequalities in outcomes for non-small cell lung cancer: the influence of clinical characteristics and features of the local lung cancer service. Thorax 2011;66:1078-84.

14 Møller H, Riaz SP, Holmberg L, et al. High lung cancer surgical procedure volume is associated with shorter length of stay and lower risks of re-admission and death: National cohort analysis in England. Eur J Cancer 2016;64:32-43. 